\title{
Research on Architectural Heritage Renewal and Protection Documentation in the UK
}

\author{
Liang Wang \\ School of Architecture, Southeast University,Nanjing,Jiangsu,China \\ School of Architecture and Civil Engineering, Nanjing Institute of Technolo- \\ gy,Nanjing,Jiangsu,China
}

KEY WORDS: Architectural Heritage, Renewal,Protection,Documentation,UK.

ABSTRACT : This paper mainly introduces the development, general features of the management and technical system of architectural heritage documentation in the UK. With the analysis of the current situation of architectural heritage documentation in China, it is believed that the recording system of UK can serve as a reference to solve many recording problems in our country, including disorganized management, disordered operation, and difficulty in the opening of archives to the public, and so on.

\section{INTRODUCTION}

Architectural heritage is recorded as a "Timely collection of monuments, construction sites and sites of the formation of the ontology, status and use of information activities". It is "the most important basic work of cultural relics protection, daily management, maintenance, engaged in basic research, planning, design and implementation of basic links and prerequisite of the protection project" and the importance of heritage protection areas already in the international consensus. Not only the Athens Charter, the Charter of Venice, the Nara Document ,Beijing Charter international convention documents to establish heritage records, open Archival heritage importance be repeatedly stressed, International Council on Monuments also specially formulated the criterion of recording sites, buildings and sites, to guide architectural heritage recording activities. Europe and the United States to protect the heritage of advanced countries are very important to the work of architectural heritage records. According to their own political system and social characteristics, the formation of a distinctive architectural heritage records. Among them, UK's architectural heritage records work management and orderly, technical specifications, system improvement;it is worth to be in the primary stage of heritage records in China for reference.

\section{UK ARCHITECTURAL HERITAGE RECORDS}

Britain's cultural heritage is divided for Listed Buildings, (mainly refers to the architectural heritage), Scheduled Ancient Monuments, (mainly refers to the archeological heritage) and Conservation Areas. To 2002, about 400 thousand Listed Buildings, 9000 Conservation Areas in the UK, which is a veritable heritage of great powers. In 1908, the British King Edward VII in the name of the Royal respectively in England, Scotland and Wales set full-time English Heritage site management organization inventory - Royal Commission on historical relics, opened the prelude to the official government management of cultural heritage recording of transactions. British administrative divisions, the largest in the UK, the most abundant heritage, can be regarded as a representative of the work of the British heritage records, the development of its records management work is divided into three stages:

Initial stage (1908-1962)

Royal Commission on the Historical Monuments of England( RCHME) establish a list of historical monuments, field survey and mapping, and perfect the management system of record. In the initial stage of heritage records, with comprehensive mapping and recording heritage focus. Initial establishment of the National nonintensive recording system (1947), to manage the record data; at the same time, the record and heritage protection work closely, set off the first time in the history of the 
United Kingdom Building record high. After 60 years of investigation, mapping, analysis and archiving, by 1970s, the local government in England has a complete set of historical monuments.

\section{Development stages $(1963,1988)$}

With a complete record of the data, the system construction of UK began to heritage data files. In 1963, RCHME set the national monuments record, NMR) and the National Archaeological Record(NAR), specializing in monuments and archeological data collection, compilation, volumes and open. Since the beginning of 1969, and have established for local planning service of monuments and records department (sites and monuments records SMRs, later renamed the historic environment records of hers), ushered in the history of the second recording climax.

\section{Integration stages (1989 so far))}

Stage Committee to record the effective use of information as the focus of work, highlighting the record in the field of education and research in the basic position of academic research. In 1989, the government will be the local agency RCHME into the leadership of the HERs. In 1994, formulated by the Department of Environmental Affairs and heritage affairs "Planning policy guidance note:Planning and the Historic Environmenl", once again stressed the importance of records on the register of all kinds of construction of, and formally incorporated into the British cultural heritage protection planning process. In 1999, the government put RCHME incorporated into UK Heritage (EH). From 1990 onwards, is committed to the establishment of NBR NAR. (national building records), NLPA (National Aerial Photography Library) database records information, including the sharing system.

\section{ARCHITECTURAL HERITAGE MANAGEMENT AND RECORD EXAMPLES}

As an ordinary member of the EH management of 3.4 million Listed Buildings, records of the British Bank of the River Thames in London of Marble Hill House and the repair history not only clearly showing the UK government heritage records the development process, can be seen record in the construction repair and protection of the core position. The seat by the design of Colen Campbell, a Scottish architect Colen Campbell stone building is the concubine of King George II of UK, founded in 1724, after the completion of two centuries in the continuous renovation and extension built in. In 1902, the United Kingdom passed a bill to protect the architectural heritage of the house, all of the house of marble hill of nonprotective intervention are prohibited. Also, the UK government bought the building and the surrounding green space, in the city of London under the supervision of the Commission will be open to the public as a public place. During this period, RCHME of buildings and their surroundings were detailed mapping, and comprehensive collection of scattered folk design drawings, historical pictures, works of art and real Voynichese book and other related information. With the UK first round record climax ended, in 1965, a large number of recorded data to critically analyze and full argument based on, "the Greater London Council" of the building and the environment were first repair, the original design drawings, art paintings and homeowner's diary literature, with the restoration of the 18th century at the beginning of building style. In 1986, the hill house was over eh, according to a copy of the Italian artist Giovanni Paolo Panini related paintings, and the restoration of the completed at the beginning of the Chinese style of interior decoration and furnishings. In 2005, for better management and utilization of the heritage, EH again commissioned AOC Limited Architectural Archaeology and the identification of the material, and the preparation of the assessment report on the value and development of today, the value of heritage through mining system, is positioned as a resort to art exhibition in the form of open to the public, and records in a variety of ways to accept the public visit as contained in each period, building repair data archives are placed in the NMR data center (search number PRN; 12271), for free public access (copy in the Museum of London); architectural history, photos and archives retrieval number can be obtained by the EH official website, the website (the old scenery Figure 1); the geographic information retrieval in the UK GIS system; and Guidebook: Marble Hill and other publications for public reading. The ordinary course of the construction of the column level is so orderly, and the records are so complete that it is entirely due to the construction of the England records management system for a hundred years. 


\section{ARCHITECTURAL HERITAGE RECORDS MANAGEMENT SYSTEM}

\section{Grade management responsibilities clear execution system}

From the point of view of transaction execution, UK 's heritage management is a typical flat network structure. According to the functions and powers of the" Historic result and it will Council for England 1983" Article 32 stipulates that UK culture sports news department's annual appropriation 1.5 billion pounds, non-governmental organizations (NGOs) eh on behalf of the government commissioned exercise of architectural heritage, including the column level architecture and registered historic site login approval and approval intervention, presided over the national records of project, management NMR, as well as around the HERs establish national record file system; specific transaction record is from EH commissioned religious groups, non-governmental organizations, research institutions and execution. EH professional surveying and mapping team is responsible for providing technical advice, record the results of the acceptance into the EH professional data system. The mode of operation of their responsibilities is both to avoid the low efficiency, and reduce the government in cultural undertakings direct interference.

Efficient use of the results of open system

\section{Multi level network data sharing system.}

$\mathrm{EH}$ and local heritage records department responsible for providing permanent file information to guide and overview, in support of the information system establishment of EH official, British old scenery, file using http://www.a2a.pro.gov.uk, UK image (HTTP: Images of england org.uk) etc. network station, provide domestic architectural heritage is located city, block position, city overview, characteristics description, web address, surrounding monuments, visit many tour, historical investigation, resource retrieval, electronic maps, aerial photos and other information, for ordinary people and experts and scholars in different educational background of the visitor use.

\section{Free and open public reading.}

Almost all of the 100 million records held by NMR are free of charge to the outside world (except for business purposes), and are available for use by the Public Research Office (Swindon) in Swindon () and the library for visitors. Data include historical photos, all UK aerial map, column construction grade description, archeological information, buildings and sites of the survey and mapping. All over the HERS will hold the ruins, monuments and landscape information files open to the outside world.

\section{Complete expert guidance system}

UK 's architectural heritage records regarding professional cooperation with the government has a long history, make clear ownership. EH as a non-governmental organization of experts, in cooperation with the Royal Institute of British Architects, Britain Council of archeology, Institute of field archeologists, the local government association officials of the archeological and Architectural Heritage Conservation Society of a professional organization, formulate a large number of architectural heritage survey technical guidelines and standards.Also, EH professional surveying and mapping team to research and to consult as its main functions, responsible for scientific research and education and training, as well as the development and utilization of new technologies, and provide related technical guidance for heritage protection records.

\section{ARCHITECTURAL HERITAGE RECORDING TECHNOLOGY SYSTEM}

In order to better guide record activities and standardize the record results, over the years, through the concerted efforts of the RCHME, EH and professional associations, has compiled a basic principles, practice guidelines and technical specifications technical documentation for the three levels, to build a clear objectives, a clear hierarchy of specialized technical refers to the system of conductors.

\section{Basic principles}

The basic criterion is to guide and programmatic document, including RCHME published the Recording Historic Buildings: A Descriptive Specification, 1991, and EH's series, Understanding historic Buildings; A Guide to Good Recording Practice ,2006 and other works, they are the most 
authoritative guidance documents, the reader groups covers almost all concerned about the architectural heritage of the public. Such as the understanding of Architectural History: guide good record for the practice of the book, in plain language, concisely discusses the meaning, object, content, time and link, and the basic method of heritage recording is introduced by an example and by drawing expression its content, in order to emphasize the record itself has the unique value and significance.

\section{Practical Guide}

The class file is refered to the record of the practice of the textbook, workbook and guide, fields such as architecture, archeology, museums, heritage technology, chemistry, physics, and computer expert or professional group compilation or written. Practice guidelines is a specialized version of the guidelines, and technical specifications of the previous study edition, covers the architectural heritage recording of various fields with time, technology system in most large and the discussion of the most parts of the system, including the historic buildings and construction of physical mapping and recording "," history of Building Surveying and mapping and record "more than 20 publications. Such as in 2006 by the East Lothian Archaeology Service Council prepared the Historic Building Recording, mainly heritage managers and record of business contract draftsman provide technology that, elaborated with emphasis how to evaluate the copy of the architectural heritage recording, not only for all records, grade and the special requirements of elaborate also lists the records required files, tables, drawings sample, to practical work very guidance.

\section{Technical Specifications}

The technical specification achieves the goal of recording technology and management science through the standard terminology, the unification procedure and the form, in these three levels of the most mandatory. Such as the "Metric Survey Specification and for English Heritage, 2003" as stipulated in the manual mapping skills, control measurement, image measurement, topographic survey and construction surveying work, application range, measurement technology operation method, technical process and data expression content; "Space for Drawing and for Text, Title Blocks on Drawing Sheets, 1999"details the mapping expression type lattice drawings; " Recommendations for the Storage and Exhibition of Archival Documents. 2000" is a complete set all kinds of results of a storage medium, storage environment and database standards and open technical requirements.

\section{SUMMARY}

In the management of UK 's heritage records, the government only plays a role of macro policy makers and financial grants, while the government authorized by the government is responsible for the overall management of the EH. In exchange and cooperation with non-governmental public organizations, non-governmental organizations, research institutions, EH has developed some technical documents to guide the operation and management of behavior, so that the concept of England heritage protection. The move not only tests and verify to record as protection is the cornerstone of the positive and effective, and we provide feasible architectural heritage protection ideas, namely the basic mapping, recording, investigation and results disclosure as a precondition. At the same time, this is the primary condition for the development of the heritage work, should be attached great importance to. Compared with the advanced countries, heritage protection in China although has passed through 80 years, but architectural heritage recording and other infrastructure work still no clear management system, a blind area and many problems exist, far did not reach the requirements of the Beijing document on "adequate records, to ensure quality, timely update, public query, transaction log stagnation has become the bottleneck of the development of cultural heritage. Therefore, the study of the British architectural heritage and protection of the century experience, for the record of the primary stage of China, especially with reference.

First of all, the work of building heritage records is a planned, step by step, and the deepening of the process, throughout the lifetime of architectural heritage. From the census stage to the establishment of a complete set of records file system, has experienced nearly a hundred years of continuous construction. This work is not easy, so it can not be instant success. China must start from the estab- 
lishment of specialized functional departments; there are plans to build management and technology two systems so that it can go on the road of standardization and scientific development.

Secondly, the construction of the architectural heritage record technology system is not compiled norms, can not be across the board, can not be formatted. Architectural heritage documentation is a continuous, dynamic, complex and multidisciplinary participation process, the numerous links, content complex, a wide range of readers. Therefore, it is the only way to set up the standard system of classification, and make the cheap criterion to guide the construction heritage records. Bogey in without the full investigation, well-organized, behind closed doors, in a fragmented and scattered way were industry specifications.

Finally, the final purpose of architectural heritage records is to apply. The experience of the advanced countries shows that, whether it is a database system or a paper file, it is a symbol of the standardization and maturity of architectural heritage records to all the public. To speed up the process of record public heritage, to achieve data sharing, is a pressing matter of the moment is the popular sentiment.

\section{ACKNOWLEDGEMENT :}

MOE (MINISTRY OF EDUCATION IN CHINA) HUMANITIES AND SOCIAL SCIENCES Foundation (Project No:15YJCZH158).

\section{REFERENCES}

1) Sheffield School of Architecture. SSoAMArch Course Handbook. Sheffield:The University of Sheffield, 2011.

2) Gänshirt C. Tools for Ideas. Berlin:Birkhauser, 2007: 17.

3)Lawson B. How Designers Think.Fourth editoion. Oxford: ArchitecturalPress, 1997: 14.

4) ICOMOS.Guide to Recording Historic Buildings,Longon:Butterworth Architecture, 1990.

5) Rchme.Recording England's Past: A Review of National and Local Sites and Monuments Records in England. London: RCHME,1993.

6) Zhu Xiaoming, Contemporary British architectural heritage protection, Shanghai: Tongji University press, 2007.

7) Ross, Michael.Planning and the Heritage :Policy and

8) Procedures .London :E .\& F.N .Spon, 1991 .P108.

9) Har rison, Richard.Manual of Heritage Management .

10) Oxford:Butterworth -Hei nemann, 1994, P198 . 